\title{
La destitución por infracción grave a la probidad administrativa en la jurisprudencia de la Contraloría General de la República
}

\author{
Daniel Silva Horta*
}

\section{RESUMEN}

El siguiente trabajo pretende determinar la forma en que la jurisprudencia de la Contraloría General de la República resuelve al momento de aplicar el artículo $N^{o} 125$ del Estatuto Administrativo, referido a la aplicación de la medida disciplinaria de destitución, como consecuencia de una infracción grave al principio de probidad administrativa. Las principales interrogantes abordadas en este artículo buscan conocer ¿Qué conductas infringen la probidad administrativa? ¿Cuándo la infracción a la probidad administrativa tiene el carácter de grave? ¿Cuál es la consecuencia de la infracción grave al principio de probidad administrativa? La metodología utilizada para responder estas preguntas fue el estudio de las decisiones de la Contraloría General de la República a la luz del principio de carrera funcionaria, consagrado en el artículo 38 inciso primero de la Constitución.

Probidad administrativa - destitución - carrera funcionaria

\section{The dismissal disciplinary action as a consequence of a serious infraction to the principle of administrative probity in the jurisprudence of Contraloría General de la República}

\begin{abstract}
The following paper aims to determine the way that jurisprudence of Contraloria General de la República resolves when applying the article number 125 of the Administrative Regulation. This is referred to the application of the dismissal disciplinary action as a consequence of a serious infraction to the principle of administrative probity. What conducts can be qualified as an offence to the principle of administrative probity? When does the principle of administrative probity infraction become serious? What is the consequence of the principle of administrative probity infraction? The study of the Contraloria General de la Republica resolutions was the main methodology to answer the above questions in the light of the "Carrera Funcionaria" principle established in the article of the thirty eight, first section of the Chilean Constitution.
\end{abstract}

Administrative probity - dismissal - service career

* Magister en Derecho, Universidad Austral de Chile. Correo electrónico: danielsilvahorta@gmail.com. Artículo recibido el 3 de mayo de 2015 y aceptado para su publicación el 30 de agosto de 2016. 


\section{INTRODUCCIÓN}

E 114 de diciembre de 1999 se publicó en el Diario Oficial la Ley $\mathrm{N}^{\circ}$ 19.653, sobre Probidad Administrativa Aplicable de los Órganos de la Administración del Estado, la que modificó la Ley No 18.575, Orgánica Constitucional de Bases Generales de la Administración del Estado, y otros cuerpos legales, desarrollando en nuestra legislación interna los principios de probidad ${ }^{1}$ y de transparencia.

Ahora bien, entre las diversas modificaciones realizadas por la Ley $\mathrm{N}^{\circ} 19.653$ destaca la relativa al actual artículo $\mathrm{N}^{\mathrm{o}} 125$ del Estatuto Administrativo ${ }^{2}$, referido a la medida disciplinaria de destitución. Acerca de esta materia, la Ley $\mathrm{N}^{\circ} 19.653$ reemplazó el encabezamiento del inciso segundo del citado artículo que decía La medida disciplinaria de destitución procederá siempre en los siguientes casos, por el actual que dice: La medida disciplinaria de destitución procederá solo cuando los hechos constitutivos de la infracción vulneren gravemente el principio de probidad administrativa, y en los siguientes casos: ${ }^{3}$.

Como es sabido, hasta antes de la modificación legal en comento, existía una importante controversia jurídica en nuestro país, en torno a si las causales de destitución del citado artículo eran o no taxativas, controversia en la que primó la tesis de la Contraloría, la que afirmaba que las causales de destitución no eran taxativas, y que por tanto los funcionarios públicos podían ser destituidos por cualquier hecho que fuera calificado por la Administración activa como una infracción grave a las obligaciones y prohibiciones funcionarias. Dicha interpretación dejaba a los funcionarios públicos de nuestro país en una situación de bastante incertidumbre respecto de su estabilidad en el empleo en la Administración pública, ya que otorgaba un importante margen de discrecionalidad a la Administración en la calificación de $\operatorname{los} \operatorname{hechos}^{4}$ y, por consecuencia, en la aplicación de la sanción de destitución.

El objetivo de la modificación al citado artículo $\mathrm{N}^{\circ} 125$, originada en la Comisión de Legislación, Justicia y Reglamento del Senado, fue restringir la aplicación de la medida disciplinaria de destitución solamente a aquellos casos en que existiese una causal de aplicación expresa, eliminando todo grado de discrecionalidad en la aplicación de la medida disciplinaria de destitución ${ }^{5}$. Como señala el profesor Pantoja, esta reforma buscó precisar su redacción, para establecer con exactitud cuándo la autoridad administrativa podía aplicar la medida disciplinaria de destitución sin invocar una causa específica. Con ello buscó restringir la interpretación uniforme que habia becho de él la jurisprudencia administrativa, al aceptar como

\footnotetext{
${ }^{1}$ Acerca de los elementos del principio de probidad administrativa, ver Barra, N., Probidad Administrativa, Lexisnexis, Santiago, 2005.

${ }^{2}$ Antiguo artículo $N^{\circ} 119$ de la Ley 18.834 de 1989, cuyo texto fue refundido, coordinado y sistematizado por el D.F.L. N $^{\circ} 29$ de 2004, del Ministerio de Hacienda.

${ }^{3}$ Idéntica modificación realizó la Ley $\mathrm{N}^{\circ} 19.653$, en el artículo $\mathrm{N}^{\circ} 123$ de la Ley $\mathrm{N}^{\circ} 18.883$ de 1989 , sobre Estatuto Administrativo de los Funcionarios Municipales.

${ }^{4}$ Al respecto, ver Aguerrea, P., "La sanción disciplinaria de destitución y sus problemas actuales", en Revista Chilena de Derecho, Pontificia Universidad Católica de Chile, Vol. 25 N 1 1, 1998, p. 17 y sgts.

${ }^{5}$ Segundo Informe de la Comisión de Constitución, Legislación, Justicia y Reglamento del Senado, Boletín $\mathrm{N}^{\circ} 1.510-07$, pp. 76 a 78.
} 
causal de destitución, de manera amplia, a cualquier hecho grave que a juicio de la autoridad debiese reprimirse con la medida de destitución ${ }^{6-7}$.

No obstante lo anterior, como ya ha sido posible apreciar, la citada Comisión acordó establecer que la medida disciplinaria de destitución resulta procedente cuando los hechos constitutivos de la infracción vulneren gravemente el principio de probidad administrativa.

Ahora bien, la mencionada legislación no señaló expresamente qué hechos constituyen una vulneración grave a la probidad administrativa. Asimismo, tampoco estableció los parámetros en virtud de los cuales debe determinarse dicha gravedad.

Todo esto nos ha llevado a centrar la atención en la aplicación de la medida de destitución por infracción grave al principio de probidad administrativa.

Lo anterior es del todo relevante, debido a que la medida disciplinaria de destitución ${ }^{8}$ es la sanción más drástica que contempla el Estatuto Administrativo para aquel funcionario que incurre en responsabilidad administrativa ${ }^{9}$, implicando como consecuencia el cese de las funciones del infractor y su inhabilitación por 5 años para ingresar o permanecer en la Administración del Estado ${ }^{10}$.

En este contexto, el presente trabajo tiene por objetivo determinar la forma en que la jurisprudencia de la Contraloría General de la República resuelve al momento de aplicar el artículo $\mathrm{N}^{0} 125$ del Estatuto Administrativo, específicamente en lo relativo a la aplicación de la medida disciplinaria de destitución, como consecuencia de una infracción grave al principio de probidad administrativa, intentando determinar qué conductas se han considerado como infracciones graves a la probidad administrativa, lo anterior a la luz de la garantía de carrera funcionaria consagrada en el artículo 38 inciso primero de la $\mathrm{CPR}^{10}$, y particularmente respecto de uno de sus elementos esenciales, cual es el derecho a la estabilidad en el empleo ${ }^{11}$.

${ }^{6}$ Pantoja R., Estatuto Administrativo Interpretado Tomo II, $7^{\circ}$ Edición Actualizada, Editorial Jurídica de Chile, 2007, p. 936.

${ }^{7}$ En relación con esta materia, resulta importante tener presente la clasificación doctrinaria que distingue entre potestades regladas y discrecionales. Al respecto, es posible señalar que en términos generales, la potestad resulta ser reglada si la Administración solo debe aplicar a un supuesto de becho la consecuencia jurídica predeterminada por la ley, ya que la norma ha determinado agotadora y exhaustivamente todas y cada una de las circunstancias de ejercicio de la potestad. Por su parte, la potestad será discrecional si la ley entrega a la Administración la posibilidad de elegir entre distintas opciones admisibles, todas las cuales serán tenidas como válidas frente al ordenamiento jurídico. En Saavedra, R., Discrecionalidad Administrativa, Thomson Reuters, Santiago, 2011, p. 14.

${ }^{8}$ La destitución es definida en el inciso primero del artículo $\mathrm{N}^{\circ} 125$ del Estatuto Administrativo como "la decisión de la autoridad facultada para hacer el nombramiento de poner término a los servicios de un funcionario.".

${ }^{9}$ Concerniente al concepto de responsabilidad administrativa, ver Bermúdez J., Derecho Administrativo General, Thomson Reuters, Santiago, 2011, p. 363.

${ }^{10}$ El Estatuto Administrativo en su artículo tercero letra f) define la carrera funcionaria como: $U n$ sistema integral de regulación del empleo público, aplicable al personal titular de planta, fundado en principios jerárquicos, profesionales y técnicos, que garantiza la igualdad de oportunidades para el ingreso, la dignidad de la función pública, la capacitación y el ascenso, la estabilidad en el empleo, y la objetividad en las calificaciones en función del mérito y de la antigüedad. 
Ahora bien, para analizar la jurisprudencia de la Contraloría General de la República, sobre destitución por falta grave a la probidad administrativa, se revisaron 378 dictámenes dictados acerca de la materia en el período comprendido entre el 14 de diciembre de 1999 (fecha de la publicación en el Diario Oficial de la Ley $\mathrm{N}^{\circ} 19.653$, conocida como Ley de Probidad) y el 31 de diciembre del $2013^{11}$.

Para estos efectos el presente trabajo se estructura en tres capítulos. En el primero se analiza la jurisprudencia administrativa relativa a la calificación de los hechos como una infracción a la probidad administrativa. En el segundo se revisan los dictámenes referidos a la ponderación de la "gravedad" de la infracción a la probidad. Finalmente, el tercer capítulo aborda las consecuencias jurídicas del hecho calificado como una infracción grave al principio de probidad administrativa.

\section{INFRACCIONES A LA PROBIDAD ADMINISTRATIVA}

\section{Conductas que infringen la probidad administrativa}

En nuestra legislación es posible encontrar una definición expresa del principio de probidad administrativa, la que se encuentra recogida en el artículo 52 inciso segundo del DFL $N^{\circ}$ 1-19.653 de 2001, que fija el texto refundido, coordinado y sistematizado de la Ley $\mathrm{N}^{\circ} 18.575$, Orgánica Constitucional de Bases Generales de la Administración del Estado ${ }^{12}$.

Sumado a lo anterior, el legislador estableció un listado de conductas que infringen “especialmente" el principio de probidad administrativa, según lo dispone el artículo 62 de la norma citada ${ }^{13}$.

${ }^{11}$ Respecto del derecho a la estabilidad en el empleo, la jurisprudencia de la Contraloría General de la República, contenida entre otros, en el dictamen $\mathrm{N}^{\circ} 16.632$ de 2011, ha sostenido que la estabilidad en el empleo consiste en que los funcionarios no pueden ser separados de sus funciones sin que una causa legal lo permita.

${ }^{12}$ La citada norma establece, El principio de la probidad administrativa consiste en observar una conducta funcionaria intachable y un desempeño honesto y leal de la función o cargo, con preeminencia del interés general sobre el particular. Por su parte, el artículo 53 agrega que El interés general exige el empleo de medios idóneos de diagnóstico, decisión y control, para concretar, dentro del orden jurídico, una gestión eficiente y eficaz. Se expresa en el recto y correcto ejercicio del poder público por parte de las autoridades administrativas; en lo razonable e imparcial de sus decisiones; en la rectitud de ejecución de las normas, planes, programas y acciones; en la integridad ética y profesional de la administración de los recursos públicos que se gestionan; en la expedición en el cumplimiento de sus funciones legales, y en el acceso ciudadano a la información administrativa, en conformidad a la ley.

${ }^{13}$ La redacción actual del artículo No 62 de ley Orgánica Constitucional de Bases Generales de la Administración del Estado contempla un catálogo de 9 conductas que infringen especialmente el principio de probidad administrativa: En efecto, la citada disposición legal actualmente establece: "Contravienen especialmente el principio de la probidad administrativa, las siguientes conductas: 1 . Usar en beneficio propio o de terceros la información reservada o privilegiada a que se tuviere acceso en razón de la función pública que se desempeña; 2. Hacer valer indebidamente la posición funcionaria para influir sobre una persona con el objeto de conseguir un beneficio directo o indirecto para sí o para un tercero; 3. Emplear, bajo cualquier forma, dinero o bienes de la institución, en provecho propio o de terceros; 4. Ejecutar actividades, ocupar tiempo de la jornada de trabajo o utilizar personal o recursos del organismo en beneficio propio o para fines 
Pues bien, atendida la amplia definición de probidad administrativa y el catálogo de conductas del artículo 62, se ha planteado la interrogante en nuestro país respecto de si la probidad administrativa se infringe únicamente mediante la realización de las conductas que la ley califica expresamente como faltas de probidad.

Al respecto, la jurisprudencia de la Contraloría ha sostenido de manera uniforme, desde el dictamen $\mathrm{N}^{\circ} 30.733$ del 2000, que las conductas descritas en el artículo 62 (antiguo artículo 64) no son taxativas. En este sentido, el mencionado dictamen señala que las actuaciones de un funcionario que impliquen una vulneración del referido principio de probidad son múltiples, y que el legislador no ha limitado a un número determinado las actuaciones funcionarias que vulneran el mismo, sino que, por el contrario, se ha preocupado de dejar claramente establecido cuáles conductas no pueden dejar de ser consideradas como una transgresión del referido principio ${ }^{14}$.

Ahora bien, en consideración a que de acuerdo a la jurisprudencia de la Contraloría las actuaciones funcionarias que vulneran el principio de probidad administrativa son múltiples, corresponde determinar si esas conductas múltiples y antijurídicas susceptibles de vulnerar el principio de probidad administrativa debieran estar expresamente descritas y prohibidas por la ley.

\section{Tipicidad de las conductas que infringen la probidad administrativa}

Respecto de esta materia es posible señalar que, desde la dictación del dictamen $\mathrm{N}^{\circ} 8.281$ de 2001, la Contraloría ha sostenido reiteradamente que el principio de tipicidad no ha sido consagrado absolutamente en materia de responsabilidad administrativa ${ }^{15}$.

ajenos a los institucionales; 5. Solicitar, hacerse prometer o aceptar, en razón del cargo o función, para sí o para terceros, donativos, ventajas o privilegios de cualquier naturaleza. Exceptúanse de esta prohibición los donativos oficiales y protocolares, y aquellos que autoriza la costumbre como manifestaciones de cortesía y buena educación. El millaje u otro beneficio similar que otorguen las líneas aéreas por vuelos nacionales o internacionales a los que viajen como autoridades o funcionarios, y que sean financiados con recursos públicos, no podrán ser utilizados en actividades o viajes particulares; 6. Intervenir, en razón de las funciones, en asuntos en que se tenga interés personal o en que lo tengan el cónyuge, hijos, adoptados o parientes hasta el tercer grado de consanguinidad y segundo de afinidad inclusive. Asimismo, participar en decisiones en que exista cualquier circunstancia que le reste imparcialidad. Las autoridades y funcionarios deberán abstenerse de participar en estos asuntos, debiendo poner en conocimiento de su superior jerárquico la implicancia que les afecta; 7. Omitir o eludir la propuesta pública en los casos que la ley la disponga; 8. Contravenir los deberes de eficiencia, eficacia y legalidad que rigen el desempeño de los cargos públicos, con grave entorpecimiento de los derechos ciudadanos ante la administración, y. 9. Efectuar denuncias de irregularidades o de faltas al principio de probidad de las que haya afirmado tener conocimiento, sin fundamento y respecto de las cuales se constatare su falsedad o el ánimo deliberado de perjudicar al denunciado”.

${ }^{14}$ Este criterio ha sido constantemente ratificado por el Órgano Contralor, como lo confirman los dictámenes $\mathrm{N}^{\mathrm{os}} 5.670$ de 2007, 52.603 de 2009, 71.484 de 2011, 57.473 de 2012 y 83.386 de 2013 , entre otros.

${ }^{15} \mathrm{Al}$ respecto, el mencionado dictamen señala: No obstante, es menester precisar respecto al principio de tipicidad, que este no ha sido consagrado absolutamente en materia de responsabilidad disciplinaria, sino solo excepcionalmente, ya que esto exigiría la descripción de conductas antijurídicas, lo que implicaría la dictación de un detallado catálogo de ilícitos administrativos, lo cual a la fecha no ha ocurrido. Confirma lo anterior el becho que ni la Ley $N^{\circ} 18.575$ 
Este criterio ha sido reiterado en diversos dictámenes, como por ejemplo los $\mathrm{N}^{\mathrm{os}}$. 58.851 de 2004, 27.259 de 2007, 57.968 de 2011 y 19.635 de 2013, entre otros.

De lo expuesto, queda en evidencia que a juicio del órgano contralor, en el ordenamiento jurídico chileno, las múltiples conductas antijurídicas que pueden infringir la probidad administrativa no se encuentran necesariamente descritas en la ley.

Lo anterior deja a los inculpados en un sumario administrativo en una situación compleja, de bastante incerteza jurídica, ya que no se sabe a priori si una determinada conducta puede infringir la probidad administrativa.

Así también lo descrito morigera bastante las consecuencias prácticas y jurídicas de la tesis sostenida por la propia Contraloría, respecto de que las causales de destitución son taxativas ${ }^{16}$.

Por lo expresado, se hace de la mayor relevancia analizar las competencias de la Administración activa y de la Contraloría, para calificar si un hecho constituye una infracción a la probidad administrativa.

\section{La ponderación de los bechos y su calificación como falta de probidad administrativa}

Respecto de la ponderación de los hechos y su calificación como falta de probidad administrativa, la jurisprudencia administrativa ha tenido diversas posturas, estas, en síntesis, se exponen a continuación:

3.1. La ponderación y calificación de los hechos como facultad privativa de la Administración

En el análisis de la jurisprudencia administrativa objeto del presente estudio se ha podido observar que una parte importante de los mencionados dictámenes han optado por reconocer un principio general de deferencia a la Administración activa en materia de responsabilidad administrativa, en virtud de esto la Contraloría reconoce una amplia facultad discrecional a la Administración ${ }^{17}$, en la ponderación de los hechos que originan un sumario administrativo ${ }^{18}$. A modo de ejemplo, el órgano contralor ha señalado

ni el Estatuto Administrativo, establecen como fundamento de la responsabilidad administrativa la comisión de una conducta descrita en la ley, ratifica lo expresado, la propia naturaleza de la responsabilidad disciplinaria, que no es sino emanación de su correlativa potestad disciplinaria, cuyo fin es la mantención y apego estricto a los deberes, probibiciones y obligaciones que gobiernan la función pública. Así entonces, debe concluirse que el principio de tipicidad consagrado en materia penal, no tiene la misma aplicación en el campo administrativo, toda vez que el ejercicio de la potestad punitiva del superior jerárquico de un servicio, o la cautela del correcto desempeño de los funcionarios, no se expresa a través de un catálogo de conductas ilícitas, sino que por intermedio de un catálogo de deberes, probibiciones y obligaciones.

${ }^{16}$ Esta tesis ha sido expuesta por la Contraloría en abundante jurisprudencia, como por ejemplo los dictámenes $\mathrm{N}^{\text {os }} 30.733$ de 2000, 39.410 de 2003, 26.502 de 2004, 52.882 de 2005 y 54.633 de 2008, entre otros.

${ }^{17}$ Sobre las distintas posiciones de la doctrina nacional acerca de la discrecionalidad administrativa, ver: Saavedra, R., op. cit., pp. 52 y siguientes.

${ }^{18}$ Acerca del deber de motivación de los actos administrativos discrecionales, reviste especial importancia el dictamen $\mathrm{N}^{\circ} 23.117$ de 2007 , de Contraloría, el que concluye que los actos administrativos dictados en ejercicio 
que es facultad de la Administración activa ponderar si la naturaleza y gravedad de los hechos exigen la instrucción de un sumario administrativo ${ }^{19}$.

En este mismo orden de ideas, la Contraloría ha reconocido que la ponderación de los medios de prueba, así como el grado de participación de los inculpados y la calificación de la falta, deben ser ponderados por quien sustancia el sumario y por la autoridad que ejerce la potestad disciplinaria, y no por la Entidad Fiscalizadora ${ }^{20}$. En concordancia con lo anterior, mediante el dictamen $\mathrm{N}^{\circ} 80.501$ de 2013, la Contraloría ha señalado que el legislador ha radicado en aquel (el alcalde), en su calidad de máxima autoridad del ente edilicio y titular de la potestad disciplinaria, las más amplias facultades para ponderar las circunstancias que ameriten imponerlas conforme a lo advertido en el proceso, por lo que esta Contraloría General no emitirá un pronunciamiento sobre tal decisión (aplica criterio contenido en el dictamen $\mathrm{N}^{\circ}$ 54.004, de 2013).

Como se puede apreciar, la jurisprudencia expuesta ha traído como consecuencia que en reiteradas ocasiones, cuando los afectados han reclamado a Contraloría que los hechos en virtud de los cuales se les formulan cargos en un sumario administrativo no constituyen una falta de probidad administrativa, el órgano contralor se ha abstenido de pronunciarse por corresponder a una materia cuyo conocimiento es privativo de la Administración activa.

\subsection{Límites a la ponderación y calificación efectuada por la Administración}

Sin perjuicio de lo expuesto en el punto anterior, es posible señalar que en diversos dictámenes el ente fiscalizador ha limitado la ponderación y calificación de los hechos que realiza la Administración activa.

En este contexto, ha señalado que si bien la potestad disciplinaria reside en la Administración activa, Contraloría puede objetar la decisión de la Administración si se vulnera la garantía constitucional del debido proceso ${ }^{21-22}$, las normas legales o reglamentarias que regulen la materia, o bien si se observa alguna arbitrariedad ${ }^{23}$.

de potestades discrecionales deben ser motivados, contar con una fundamentación racional y encontrarse plenamente a justados a la normativa constitucional y legal vigente. En Cordero L., Decisiones Destacadas en Derecho Administrativo, Tratado de Jurisprudencia y Doctrina, Thomson Reuters, Santiago, 2012, pág. 456.

${ }^{19}$ Dictámenes $\mathrm{N}^{\text {os }} 33.880$ de 2010 y 43.113 de 2011.

${ }^{20}$ Al respecto destaca el dictamen $\mathrm{N}^{\circ} 48.369$ de 2012, el que establece: La ponderación de los hechos y la determinación de la gravedad y grado de responsabilidad que en ellos cabe a los imputados, son materias cuyo conocimiento corresponde privativamente a los órganos de la Administración activa.

${ }^{21}$ Dictámenes $\mathrm{N}^{\text {os }} 5.212$ de 2009 y 17.746 de 2009.

${ }^{22}$ Respecto de la aplicabilidad de las garantías constitucionales como el debido proceso, en el "derecho penal administrativo", ver Letelier M., "La potestad Sancionatoria del Estado en el Marco de las Garantías Constitucionales.", en Revista de Derecho Administrativo, No 5, LegalPublishing, 2011, pp. 159 y siguientes; y acerca de los elementos del debido proceso, ver: Navarro E., "El debido proceso en la Jurisprudencia del Tribunal Constitucional”, en Arancibia J., Martínez J. y Romero A. (coordinadores), Litigación Pública, Colección de Estudios de Derecho Público, LegalPublishing, Santiago, 2011, pp. 11 a 36.

${ }^{23}$ Dictamen $\mathrm{N}^{\mathrm{o}} 38.209$ de 2013. 
En concordancia con lo anterior y particularmente respecto de la garantía constitucional del debido proceso, el ente fiscalizador ha señalado por ejemplo en el dictamen $\mathrm{N}^{\mathrm{o}} 17.746$ de 2009, lo siguiente: Siendo ello así, es de competencia de esta Entidad velar porque los procedimientos sumariales se ajusten estrictamente al principio de juridicidad, consagrado en los artículos $6^{\circ}, 7^{\circ}$ y 19, $N^{\circ} 3$, de la Carta Fundamental, y en el artículo $2^{\circ}$ de la Ley $N^{o}$ 18.575, de Bases Generales de la Administración del Estado, vale decir, que se substancien con estricto apego a la legislación respectiva, emitiendo decisiones justas, exentas de discriminaciones arbitrarias -luego de considerarse todos los hechos fehacientemente establecidos-, y aplicando sanciones que se correspondan con la gravedad de los hechos y la responsabilidad del servidor en ellos, resguardando, de este modo, el principio de la proporcionalidad contemplado en el artículo 120 de la Ley $N^{\circ} 18.883$, cuerpo estatutario de los funcionarios municipales.

Como es posible apreciar, en determinadas circunstancias Contraloría ha reconocido por medio de su propia jurisprudencia una facultad bastante amplia para representar la decisión de la Administración activa, la que no se limita a cautelar aspectos de forma del proceso disciplinario, sino que también abarca aspectos de fondo como la "justicia" y "proporcionalidad" 24 de la decisión de la Administración.

En concordancia con lo anterior, Contraloría ha emitido diversos dictámenes, en ellos no se priva de pronunciarse acerca de la ponderación de los hechos y la calificación de los mismos como falta a la probidad administrativa, sino que por el contrario, se pronuncia expresamente respecto de si determinado hecho constituye una infracción al principio de probidad $^{25}$.

${ }^{24}$ Respecto de la representación de la decisión de la Administración, por falta de proporcionalidad de la profesora Camacho G., ha señalado: Con todo, no se puede dejar de advertir la utilización que la Contraloría ha becho de este principio para imponer, en algunas ocasiones su criterio de ponderación a la Administración activa, a pesar de que el artículo $21 \mathrm{~B}$ de la LOCCGR le probíbe pronunciarse sobre "los aspectos de mérito o de conveniencia de las decisiones políticas o administrativas". Esta situación puede significar, en algunos casos el rechazo de legítimas opciones administrativas que se juzgan incompatibles con valores que la Contraloría entiende preferible. Todo lo cual, genera un riesgo de limitar o desplazar indebidamente la discrecionalidad administrativa hacia el Órgano de Control, función que con toda evidencia no le corresponde". En Camacho G., "La Actividad Sustancial de la Administración del Estado, en Pantoja B. (coordinador), Tratado de Derecho Administrativo Tomo IV, LegalPublishing, Santiago, 2010, p. 80.

25 Sobre este punto resulta interesante lo dispuesto por la Contraloría en dictamen $N^{0} 49.580$ de 2008. En dicho caso el afectado por la medida disciplinaria de destitución le planteó a Contraloría que su conducta no podía ser calificada como falta de probidad, ya que con su actuar no robó, hurtó, se apropió de dineros públicos, defraudó al municipio, dañó el patrimonio municipal ni ofendió a funcionarios. Sin embargo, Contraloría desestimó esta argumentación, manifestando que las acciones que infringen el principio de probidad no solamente son las que enuncia el interesado, sino que todas aquellas que impliquen contravenir la conducta funcionaria intachable y el desempeño honesto y leal en la función o cargo, que la ley demanda que el servidor observe y cumpla. En el mismo tenor se pueden citar los dictámenes N ${ }^{\text {os }} 60.962$ de 2009 y 42.372 de 2010. 


\section{LA PONDERACIÓN DE LA GRAVEDAD DE LA FALTA} DE PROBIDAD ADMINISTRATIVA

Como ya se dijo, la Administración activa ${ }^{26}$ es la facultada para calificar si un hecho infringe el principio de probidad administrativa, sin perjuicio de las atribuciones de control del Ente Fiscalizador.

Ahora bien, respecto de la calificación de si la infracción al principio de probidad administrativa es de carácter grave, la jurisprudencia administrativa ha mantenido esta especie de deferencia hacia la Administración activa, estableciendo en su jurisprudencia mayoritaria que corresponde a la autoridad calificar la gravedad del hecho ${ }^{27}$.

En este sentido, mediante dictamen $\mathrm{N}^{\circ} 9.274$ de 2012, señala: En este contexto, es dable concluir que corresponde a la autoridad administrativa la calificación de las irregularidades como una grave infracción a la probidad, tal como ha acontecido en la especie.

Lo anterior es muy importante, debido a que Ley $\mathrm{N}^{\circ} 19.653$, sobre Probidad Administrativa Aplicable de los Órganos de la Administración del Estado, no explicita en qué circunstancias debe considerarse que una infracción a la probidad administrativa es de carácter grave, ni tampoco describe los parámetros en virtud de los cuales se puede determinar dicha gravedad.

\section{Conductas calificadas como infracciones graves al principio de probidad administrativa}

Teniendo ya presente que la ley no define qué se entiende por infracción grave a la probidad administrativa, así como tampoco señala los criterios por los cuales puede determinarse la gravedad de una conducta y que además, de acuerdo con la jurisprudencia del órgano contralor, corresponderá a la Administración activa calificar la gravedad de la conducta, resulta del todo relevante conocer qué conductas han sido calificadas por Contraloría como infracciones graves a la Probidad Administrativa.

En este contexto, como se podrá observar, las conductas que han sido calificadas como faltas graves a la probidad administrativa son numerosas y de muy distinta naturaleza y magnitud. Por lo anterior, a continuación procederemos a enunciar las citadas conductas:

1.1. Conductas relacionadas con maniobras dolosas para obtener beneficio patrimonial, propio o de terceros: Falsificación de firmas, para obtener beneficio personal (dictamen $\mathrm{N}^{\circ} 32.339$ de 2000); Ordenar pago de horas extras no realizadas (dictamen $\mathrm{N}^{\circ} 17.860$

26 "La administración activa está constituida por la línea de acción pública directa, por los órganos y organismos encargados de resolver directamente los problemas generales de la población del país”. En Pantoja R., La Organización Administrativa del Estado, Editorial Jurídica de Chile, Santiago, 1998, p. 347.

${ }^{27}$ Así lo ha dejado establecido en los siguientes dictámenes: 6.100 de 2002; 2.890 de 2007; 52.603 de 2009; 57.295 de 2009; 1.603 de 2010 y 77.577 de 2010. 
de 2008) y cargar combustible del Servicio en vehículo particular (dictamen $\mathrm{N}^{\circ} 547$ de 2007$)^{28}$.

1.2. Conductas relacionadas con el uso indebido de bienes e información institucional: Uso indebido del teléfono institucional, para fines particulares (dictamen $\mathrm{N}^{\circ} 30.952$ de 2005) y reproducción y almacenamiento de material pornográfico en computador institucional (dictamen $\mathrm{N}^{\circ} 19.206$ de 2012).

1.3. Conductas relacionadas con agresiones físicas, psicológicas y acoso sexual: Agresiones físicas a otro funcionario (dictamen $\mathrm{N}^{\circ} 6.100$ de 2002) y acoso sexual de profesor universitario a estudiante (dictamen $\mathrm{N}^{\circ} 41.606$ de 2002).

1.4. Conductas relacionadas con abogados: Abogado que patrocina acción judicial en contra del municipio en el cual presta servicios (dictamen $\mathrm{N}^{\circ} 42.174$ de 2008) y abogado que tramita de manera negligente las causas a su cargo (dictamen $\mathrm{N}^{\circ} 45.262$ de $2012)^{29}$.

1.5. Conductas relacionadas con profesionales de la salud: Efectuar tocamientos indebidos a pacientes (dictamen $\mathrm{N}^{\circ} 27.918$ de 2002) y negligencias médicas (dictámenes $\mathrm{N}^{\text {os }} 53.223$ y 83.386 , ambos de 2012).

1.6. Conductas relacionadas con la vida privada: Funcionaria de Gendarmería de Chile, sorprendida por personal de Carabineros de Chile, fuera de su lugar de trabajo y de su horario de trabajo, en un vehículo, en una conducta que constituye una ofensa a la moral y a las buenas costumbres, oportunidad en que se negó a entregar su identidad y, luego, proporcionó la de su hermana (dictamen $\mathrm{N}^{\mathrm{o}} 1.929$ de 2012) y funcionario que se involucró en hechos que dieron origen a una investigación criminal por obtención de servicios sexuales de menores de edad, con exposición mediática, sin cautelar la imagen, honor, prestigio y ascendencia social de su puesto (dictamen $\mathrm{N}^{\circ} 77.441$ de 2013).

${ }^{28}$ Otras conductas calificadas como faltas graves a la probidad administrativa, y que dicen relación con maniobras dolosas para obtener beneficios patrimoniales propios o para terceros son las siguientes: Apropiación indebida de recursos públicos (dictamen $\mathrm{N}^{\circ} 29.179$ de 2002); Solicitar pago en su beneficio para realización de trámites institucionales (dictamen $\mathrm{N}^{\circ} 72.900$ de 2013); Funcionario de S.I.I. que realiza maniobras fraudulentas para que terceros obtengan devoluciones indebidas de impuestos (dictamen $\mathrm{N}^{\circ} 28.880$ de 2002); Adulteración de documento para cobrar pensión de beneficiario fallecido (dictamen $\mathrm{N}^{\circ} 39.536$ de 2011); Fiscalizador que informa previa e indebidamente a terceros la oportunidad en que se efectuarán las fiscalizaciones de su Servicio (dictamen $N^{\circ} 59.462$ de 2011); Presentar licencia médica en Servicio, para durante dicha licencia, realizar labores remuneradas en otra institución (dictamen $\mathrm{N}^{\circ} 42.372$ de 2010) y adulterar liquidaciones de sueldo para obtener crédito (dictamen $\mathrm{N}^{\circ} 77.253$ de 2013).

${ }^{29}$ Otras conductas calificadas como faltas graves a la probidad administrativa, y que dicen relación con Abogados son las siguientes: Abogado que a falta de días administrativos y feriados, presentó licencia médica en el Servicio, para realizar viaje previamente planificado al extranjero (dictamen $\mathrm{N}^{\circ} 60.701$ de 2012). 
1.7. Otras conductas: Negligencia en entrega de licencias de conducir (dictamen $\mathrm{N}^{\circ}$ 65.284 de 2011); Negligencia en control de asistencia de funcionarios a su cargo (dictamen $\mathrm{N}^{\circ} 57.473$ de 2012); Atrasos reiterados (dictamen $\mathrm{N}^{\circ} 46.592$ de 2000) ${ }^{30}$.

Como ha quedado de manifiesto, la jurisprudencia administrativa ha sido muy abundante y variada a la hora de reconocer conductas que atentan gravemente contra el principio de probidad administrativa, incluyéndose en dicho concepto variadas y diversas conductas ${ }^{31}$.

Lo anterior da cuenta de que en nuestra legislación el carácter reglado de la potestad de destitución se encuentra bastante mermado. En efecto, la gran cantidad de conductas que se han reconocido como infracciones graves a la probidad administrativa parecieran dar a entender que el concepto de infracción grave a la probidad administrativa es un concepto jurídico indeterminado ${ }^{32}$, lo que implica que será la Administración activa, la Contraloría, o en su defecto el Juez, el llamado a precisar si una determinada conducta se encuentra incluida en dicho concepto ${ }^{33}$.

\section{Limites a la ponderación y calificación efectuada por la administración}

Como ha sido posible apreciar, existe numerosa jurisprudencia administrativa, en la que Contraloría ha ratificado la calificación jurídica efectuada por la Administración

${ }^{30}$ Otras conductas calificadas como infracciones graves a la probidad administrativa: Negligencia de Educadora de Párvulo, que produce como resultado la muerte de menor (dictamen No 60.497 de 2005); Contratación mediante trato directo, sin ser ingresada al portal Mercado Público y sin tres cotizaciones (dictamen $\mathrm{N}^{\circ} 178$ de 2007); No ejercer suficiente supervisión y control jerárquico, lo que trajo como consecuencia un perjuicio al patrimonio fiscal (dictamen $\mathrm{N}^{\circ} 24.970$ de 2009); Intervenir en asunto en que existe falta de imparcialidad (dictamen $N^{\circ} 51.764$ de 2011); Funcionario que en su calidad de Ministro de Fe certifica haber realizado notificaciones que no fueron efectuadas (dictamen $\mathrm{N}^{\circ} 42.027$ de 2000); Funcionaria de S.I.I que autoriza facturas a contribuyente que figuraba con observación de no timbrar (dictamen $\mathrm{N}^{\circ} 24.682$ de 2002).

31 Sobre esta variada jurisprudencia administrativa en materia de probidad administrativa, el autor nacional Ramón Huidobro, ha señalado: La descripción del tratamiento jurisprudencial, realizado por la Contraloría General de la República, en relación con la probidad administrativa, deja abiertas muchas interrogantes respecto del método de interpretación utilizado. Algunas de ellas son por ejemplo: ¿Existe un voluntarismo interpretativo?, ¿Literalismo jurídico o interpretación del derecho?. En Huidobro, S., "Derecho y Administración Comunal", en Pantoja B. (coordinador), Tratado de Derecho Administrativo Tomo III, LegalPublishing, Santiago, 2011, pp. 150 y 151.

${ }^{32}$ Respecto de la distinción entre discrecionalidad y conceptos jurídicos indeterminados, el autor nacional Rubén Saavedra recuerda: No existe consenso en la doctrina administrativa acerca de la relación existente entre discrecionalidad administrativa y conceptos jurídicos indeterminados. Así, para algunos autores se trata de dos categorías conceptuales claramente diferenciadas, y para otros más bien, de la expresión de un matiz en un fenómeno genérico y común. En Saavedra, R., op. cit., pp. 16 y siguientes.

${ }^{33}$ Respecto del uso general de conceptos jurídicos indeterminados el profesor Moraga señala que el uso general de los conceptos jurídicos indeterminados por parte del legislador traslada el poder decisorio efectivo desde el Parlamento hacia la Administración, o también, el juez. En Moraga, C., "La Actividad Formal de la Administración del Estado", en Pantoja B. (coordinador), Tratado de Derecho Administrativo Tomo VII, LegalPublishing, Santiago, 2010, p. 39. 
activa, dejándose establecido que determinados hechos constituyen una infracción grave a la probidad administrativa.

Sin perjuicio de lo anterior, existe interesante pero escasa jurisprudencia administrativa en virtud de la cual el órgano contralor ha declarado que una determinada conducta no debe ser calificada como una infracción grave al principio de probidad administrativa. Los argumentos esgrimidos por Contraloría para representar la calificación efectuada por la Administración activa son en síntesis los siguientes:

- La conducta no es grave porque no hay mala fe del inculpado (dictámenes $\mathrm{N}^{\text {os }} 37.741$ de 2003 y 85.689 de 2013 ).

- La conducta no es grave porque produce un daño menor y es realizada en forma esporádica (dictamen $\mathrm{N}^{\circ} 61.816$ de 2009) ${ }^{34}$.

- La conducta no es grave debido a la ausencia de beneficios patrimoniales del infractor (dictamen $\mathrm{N}^{\circ} 20.439$ de 2004).

- La conducta no es grave, porque el inculpado incurre en falta, para satisfacer necesidad del servicio y no interés personal (dictamen $\mathrm{N}^{\circ} 3.025$ de 2012).

- La infracción contenida en la letra g) (Ejecutar actividades, ocupar tiempo de la jornada de trabajo o utilizar personal, material o información reservada o confidencial del organismo para fines ajenos a los institucionales) del artículo 84 de la Ley $\mathrm{N}^{\circ} 18.834$, no dice relación con una infracción grave al principio de probidad administrativa (dictamen $\mathrm{N}^{\circ} 45.364$ de 2009).

- Las infracciones contenidas en las letras f) (Obedecer las órdenes impartidas por el superior jerárquico); e i) (Observar una vida social acorde con la dignidad del cargo) del artículo 61 de la Ley $\mathrm{N}^{\circ} 18.834$, no dicen relación con una infracción grave al principio de probidad administrativa (dictamen $\mathrm{N}^{\circ} 44.908$ de 2009).

- La conducta no es grave porque no se acreditó un actuar deshonesto, que privilegie el beneficio particular por sobre el del servicio al que pertenece el inculpado (dictamen $\mathrm{N}^{\circ} 54.642$ de 2005)

Como es posible advertir, si bien la Contraloría en determinados casos ha limitado la calificación jurídica efectuada por la Administración, este control es todavía precario, situación que se manifiesta en la falta de criterios uniformes dentro de la propia jurisprudencia administrativa. En este sentido, es posible observar que los argumentos que han sido esgrimidos para controlar la calificación efectuada por la Administración Activa, en muchos casos no son congruentes con el resto de la propia jurisprudencia administrativa. Al respecto, es posible señalar que mientras en los dictámenes $\mathrm{N}^{\text {os }} 37.741$ de $2003 \mathrm{y}$ 85.689 de 2013, el órgano de control afirma que si no hay mala fe, no es posible calificar el hecho como una infracción grave a la probidad administrativa, en otros dictámenes

${ }^{34}$ Interesante caso en que a uno de los imputados no se le aplicó una medida expulsiva por haberse acreditado que su falta tenía menos gravedad que la de los otros afectados, toda vez que las bajas de rendimiento del vehículo a su cargo, producto de la aludida maniobra dolosa en el suministro de combustible, eran de menor entidad y más esporádicas que las acreditadas al resto de los implicados. 
se han calificado como infracciones graves al mencionado principio, conductas en que no existe mención alguna a dicho elemento, sino que a meras negligencias del infractor, como la relativa al empleado negligente en el control de asistencia de los funcionarios a su cargo (dictamen $\mathrm{N}^{\circ} 57.473$ de 2012).

A mayor abundamiento, resulta pertinente mencionar que si bien mediante dictamen $\mathrm{N}^{\circ} 45.364$ de 2009 se ha establecido que la infracción contenida en la letra g) (Ejecutar actividades, ocupar tiempo de la jornada de trabajo o utilizar personal, material o información reservada o confidencial del organismo para fines ajenos a los institucionales) del artículo 84 de la Ley $\mathrm{N}^{\circ} 18.834$ no dice relación con una infracción grave al principio de probidad administrativa, en otro dictamen (dictamen $\mathrm{N}^{\circ} 30.952$ de 2005) se ha calificado como una infracción grave al principio de probidad administrativa el uso indebido del teléfono institucional, para fines particulares. Por otra parte, es posible señalar que si bien mediante dictamen $\mathrm{N}^{\circ} 20.439$ de 2004, el órgano de control ha señalado que la conducta no es grave debido a la ausencia de beneficios patrimoniales del infractor, mediante dictamen $\mathrm{N}^{\circ} 1.929$ de 2012 se ha calificado como una infracción grave al principio de probidad administrativa un hecho relativo a la vida privada de la funcionaria, en que no ha existido beneficio patrimonial alguno para el infractor.

Lo expuesto, deja de manifiesto que no es certera la jurisprudencia administrativa en cuanto a los elementos que deben estar presentes para que un hecho pueda ser calificado como una infracción grave al principio de probidad administrativa, sino que todo lo contrario, se observan importantes contradicciones en la misma, al analizar los distintos casos en que se ha pronunciado.

\section{LA DESTITUCIÓN COMO CONSECUENCIA DE LA FALTA GRAVE}

\section{A LA PROBIDAD ADMINISTRATIVA}

Respecto de esta materia, la jurisprudencia administrativa mayoritaria ha señalado que calificado un hecho como falta grave a la probidad administrativa, la Administración activa no puede aplicar una sanción distinta a la destitución ${ }^{35}$.

El fundamento que sustenta esta tesis de Contraloría es que la sanción para quien incurrió en una grave contravención al principio de probidad está expresamente establecida en la ley, razón por la que la autoridad no puede considerar ningún tipo de circunstancia atenuante, para rebajar esta sanción.

A modo de ejemplo, se puede citar el dictamen $\mathrm{N}^{\circ} 49.580$ de 2008, el que señala: En este contexto, el Alcalde de la Municipalidad de Santiago se encontraba en el imperativo de aplicar al recurrente la medida disciplinaria de destitución, atendido que este, conforme se advierte de las piezas sumariales en estudio, incurrió en una grave contravención al principio de probidad,

35 Así lo ha manifestado en los dictámenes $\mathrm{N}^{\text {os }} 32.598$ de 2005; 33.135 de 2005; 38.647 de 2005; 22.312 de 2006; 28.756 de 2006; 29.651 de 2006; 47.561 de 2006; 49.465 de 2006; 547 de 2007 y 49.580 de 2008 , entre otros. 
cuya sanción está expresamente establecida en la ley, sin que correspondiera entrar a calificar su trayectoria funcionaria como circunstancia atenuante.

Es decir, acreditada la ocurrencia de un hecho, que la autoridad califica como grave contravención a la probidad administrativa, la Administración se encuentra en el imperativo legal de aplicar la destitución.

En concordancia con lo señalado previamente, por regla general Contraloría ha considerado que no es posible la ponderación de atenuantes en caso de infracción grave a la probidad administrativa, debido a que la ley asigna una medida disciplinaria específica para esta sanción, por lo que la autoridad se encuentra en el imperativo de disponerla ${ }^{36}$.

No obstante lo anterior, existe jurisprudencia administrativa que escapa a esta regla general, y que en virtud de la existencia de circunstancias atenuantes ha permitido la aplicación de una sanción distinta, aun cuando el hecho haya sido calificado como una infracción grave a la probidad administrativa.

Al respecto, el dictamen $\mathrm{N}^{\circ} 77.240$ de 2012, en lo pertinente, señala expresamente: Por otra parte, en lo que atañe al reclamo por la falta de proporcionalidad de la sanción aplicada y no baberse considerado las circunstancias atenuantes que, a juicio de la recurrente, concurrían a su favor, corresponde indicar que la reiterada jurisprudencia de este órgano de control, contenida, entre otros, en los dictámenes $N^{o}$ s. 33.054, de 2000, 22.509, de 2005 y 49.342, de 2009, ha sostenido que cuando la ley asigna una medida disciplinaria específica para una determinada infracción, como acontece respecto de la falta a la probidad, la autoridad administrativa se encuentra en el imperativo legal de disponerla, sin perjuicio que, en virtud de la potestad disciplinaria que posee, determine, a través de un acto administrativo fundado, rebajarla imponiendo en sustitución de ella una sanción no expulsiva, atribución que, en la situación que se analiza, el alcalde resolvió no ejercer.

Como es posible advertir, respecto de las circunstancias atenuantes que permitirían rebajar la calificación de la gravedad de la falta de probidad, las dos tesis principales que ha sostenido Contraloría, son las siguientes:

1) En caso de infracción grave a la probidad administrativa, la autoridad se encuentra impedida de ponderar circunstancias atenuantes, por lo que se encuentra obligada a aplicar la medida disciplinaria de destitución.

2) En caso de infracción grave a la probidad administrativa, la autoridad se encuentra facultada para, mediante un razonamiento fundado, rebajar la sanción a aplicar ${ }^{37}$.

${ }^{36}$ Al respecto el dictamen $\mathrm{N}^{\circ} 47.412$ de 2007, señala: Por otra parte, respecto a lo manifestado por la recurrente, relativo a la existencia de atenuantes que la beneficiarían, cabe señalar que cuando la ley asigna una medida disciplinaria específica para determinada infracción, la autoridad administrativa se encuentra en el imperativo de disponerla, no pudiendo ejercer las atribuciones privativas que le permiten determinar aquélla que, a su juicio, merecería el comportamiento anómalo observado por la afectada, ni menos ponderar circunstancias que eventualmente aminoren su responsabilidad funcionaria. Este criterio también se encuentra contenido en dictamen $\mathrm{N}^{\circ} 2.890$ de 2007 , entre otros.

${ }^{37}$ En este mismo sentido, también falló la I. Corte de Apelaciones de Valparaíso en causa Rol 547 de 2001, señalando que en un caso de infracción grave a la probidad administrativa, la irreprochable conducta anterior del funcionario, no trae como necesaria consecuencia que el jefe del servicio deba rebajar las sanciones 
Pese a lo anterior es posible observar una tercera tesis de Contraloría sobre la materia, contenida en dictamen $\mathrm{N}^{\circ} 1.713$ de 2007 , en virtud de este no es facultativo para la autoridad ponderar las circunstancias atenuantes, sino que es un deber legal que de no ser cumplido, implica que la propia autoridad incurra en falta de $\operatorname{probidad}^{38}$.

Sin embargo, se debe tener presente que Contraloría en diversas ocasiones ha procedido a representar la ilegalidad de la aplicación de una medida disciplinaria de destitución por falta grave de probidad administrativa, por circunstancias distintas a la calificación de la gravedad, como por ejemplo, por falta de precisión de los cargos (dictamen $\mathrm{N}^{\circ} 10.483$ de 2008); así como también por falta de prueba de los cargos (dictámenes $\mathrm{N}^{\text {os }} 26.083$ de 2005 y 7.950 de 2013).

\section{Conclusiones}

De lo hasta aquí señalado, y particularmente de la jurisprudencia revisada, es posible formular algunas conclusiones relevantes para esta materia:

1) De acuerdo con la jurisprudencia administrativa, el principio de probidad administrativa puede ser infringido mediante múltiples conductas, las que no requieren estar expresamente tipificadas en la ley como conductas antijurídicas.

2) La Administración activa goza en principio de una amplia facultad discrecional para calificar si una determinada conducta vulnera el principio de probidad administrativa, así como también para calificar la gravedad de la infracción.

dispuesta por la ley, quedando entregado a su discrecionalidad, de acuerdo con los antecedentes existentes en cada sumario, la apreciación de la gravedad de la falta, y la sanción que impondrá en ese caso particular. En Departamento de Estudios Jurídicos Punto Lex., Jurisprudencia Judicial Administrativa, Tomo I, Thomson Reuters, Santiago, 2009, pág. 214.

${ }^{38} \mathrm{El}$ citado dictamen fue emitido por el órgano contralor a propósito de una presentación efectuada por el inculpado, con motivo del registro del decreto alcaldicio mediante el cual se le aplica la medida disciplinaria de destitución, por infracción grave a la probidad administrativa. Pues bien, en dicha instancia Contraloría dictamina que la Administración deberá proceder a dejar sin efecto el decreto mencionado y en su reemplazo dictar otro que aplique al inculpado, al término de estos autos, una sanción que no implique su desvinculación del Municipio. El fundamento de la decisión de Contraloría, radica en que si bien las acciones que describen constituyen faltas a la probidad, no tienen, sin embargo, la entidad suficiente que permitan sostener que se trata de improbidades cuya única sanción aplicable sea la medida disciplinaria de destitución. Asimismo, agrega: Sobre este punto, es oportuno recordar que la referida sanción disciplinaria de destitución implica que el funcionario afectado no puede volver a prestar servicios en algún Organismo de la Administración Pública, sino una vez transcurridos, en términos generales, 5 años desde su aplicación, y mediando, además, decreto supremo de rehabilitación. Por tal razón, atendida la magnitud de los efectos jurídicos y de becho que genera dicha medida, para que pueda ser legítimamente aplicada, es exigible que del mérito del sumario, una vez ponderadas las circunstancias atenuantes y/o agravantes, aparezca indubitada e irrefutablemente que no existe otra sanción que sea correspondiente a la falta funcionaria; es decir, que la única medida sancionatoria que puede ser ordenada atendida la entidad de la acción indebida, es el alejamiento del servicio. De lo contrario, es la autoridad la que incurre en una grave omisión e indebido ejercicio de sus facultades, lo que claramente se traduce en una inobservancia del principio de probidad. 
3) No existen criterios uniformes en la jurisprudencia administrativa respecto de los límites de la calificación que realiza la autoridad, ya que cuando se ha reclamado acerca de este aspecto, incluso en algunos casos Contraloría se ha abstenido de pronunciarse, por ser un aspecto de mérito privativo de la Administración activa.

4) Si bien el órgano contralor ha intentado tímidamente controlar la calificación jurídica de los hechos efectuada por la Administración activa, es posible apreciar en la jurisprudencia una precariedad en la técnica jurídica de dicho control, lo que se manifiesta en la diversidad de conductas que han sido calificadas como infracciones graves al principio de probidad administrativa (con o sin dolo, con o sin beneficio propio, con o sin perjuicio al patrimonio fiscal), así como también en la incongruencia existente en la propia jurisprudencia, respecto de los elementos que deben concurrir para que un hecho sea calificado como una infracción grave al referido principio.

5) El amplio margen de discrecionalidad del cual goza la Administración activa, para ponderar los hechos y calificarlos como faltas graves a la probidad administrativa, así como la falta de criterios jurisprudenciales administrativos uniformes, que limiten esta facultad, permiten concluir que la modificación realizada por la Ley $\mathrm{N}^{\circ} 19.653$, al artículo $\mathrm{N}^{\circ} 125$ del Estatuto Administrativo, referido a la medida disciplinaria de destitución, no cumplió con el objetivo explicitado por la Comisión de Legislación, Justicia y Reglamento del Senado, cual era eliminar todo grado de discrecionalidad en la aplicación de la medida disciplinaria de destitución.

6) Lo expuesto nos permite finalmente colegir que uno de los elementos esenciales del derecho a la carrera funcionaria, cual es la estabilidad en el empleo, se encuentra seriamente lesionado en la actualidad por la legislación relativa a la destitución por falta grave a la probidad administrativa.

\section{BIBLIOGRAFÍA}

Aguerrea, P., "La sanción disciplinaria de destitución y sus problemas actuales", en Revista Chilena de Derecho, Pontificia Universidad Católica de Chile, Vol. $25 \mathrm{~N}^{\circ} 1,1998$.

Barra, N., Probidad Administrativa, LexisNexis, Santiago, 2005.

Bermúdez, J., Derecho Administrativo General, Thomson Reuters, Santiago, 2011.

Cordero, L., Decisiones Destacadas en Derecho Administrativo, Tratado de Jurisprudencia y Doctrina, Thomson Reuters, Santiago, 2012.

Huidobro, S., "Derecho y Administración Comunal", en Pantoja B. (coordinador), Tratado de Derecho Administrativo Tomo III, LegalPublishing, Santiago, 2011.

Letelier M., "La Potestad Sancionatoria del Estado en el Marco de las Garantías Constitucionales", en Revista de Derecho Administrativo, N 5, LegalPublishing, 2011.

Moraga, C., "La Actividad Formal de la Administración del Estado", en Pantoja B. (coordinador), Tratado de Derecho Administrativo Tomo VII, LegalPublishing, Santiago, 2011.

Navarro, E., "El debido proceso en la Jurisprudencia del Tribunal Constitucional", en Arancibia J., Martínez J. y Romero A. (coordinadores), Litigación Pública, Colección de Estudios de Derecho Público, LegalPublishing, Santiago, 2011. 
Pantoja, R., Estatuto Administrativo Interpretado Tomo II, $7^{\circ}$ Edición Actualizada, Editorial Jurídica de Chile, 2007.

, La Organización Administrativa del Estado, Editorial Jurídica de Chile, Santiago, 1998.

SaAvedra, R., Discrecionalidad Administrativa, LegalPublishing, Santiago, 2011. 
